\title{
KURANG OPTIMALNYA PEMBAKARAN PADA AUXILIARY BOILER YANG MENGHAMBAT PROSES BONGKAR MUATAN DI MT. ENDURO
}

\author{
Sarifuddin $^{\mathrm{a}}$, Wisnu Handoko ${ }^{\mathrm{b}}$ dan Wida Yuliati \\ ${ }^{a}$ Dosen Program Studi Teknika PIP Semarang \\ ${ }^{\mathrm{b}}$ Dosen Program Studi Nautika PIP Semarang \\ ${ }^{c}$ Taruna (NIT.49124527.T) Program Studi Teknika PIP Semarang
}

\begin{abstract}
ABSTRAK
Ketel uap bantu di kapal merupakan salah satu permesinan bantu yang memiliki peranan penting untuk menghasilkan uap panas yang berkualitas. Kegunaan dari uap ini adalah untuk memanaskan bahan bakar, ruangan, zat cair dalam tangki, fresh water jacket cooling, menggerakkan pompa turbin dan lain sebagainya. Agar menghasilkan uap yang berkualitas dan dalam jumlah banyak maka dibutuhkan pembakaran yang sempurna pada ketel uap bantu. Penelitian ini dilakukan di kapal MT. Enduro. Sumber data yang diperoleh adalah data primer yang diperoleh langsung dari tempat penelitian serta data sekunder yang diperoleh dari literatur-literatur yang berkaitan dengan judul penelitian. Hasil kerja yang diperoleh dari penelitian ini menunjukkan bahwa tidak optimalnya pembakaran pada ketel uap bantu disebabkan karena temperatur bahan bakar yang tidak sesuai yang disebabkan oleh rusaknya heater, kurangnya suplai udara disebabkan oleh rusaknya elektromotor, macetnya fire damper disebabkan oleh rusaknya magnetic contactor, nozzle burner kotor disebabkan oleh bahan bakar yang masuk ke dalam nozzle burner tidak melalui proses pemisahan di dalam purifier.
\end{abstract}

\section{Kata kunci: Auxiliar boiler, identifikasi, bongkar muat}

\section{PENDAHULUAN}

Transportasi melalui jalur laut diera globalisasi ini memegang peranan penting dalam perdagangan Internasional. Dengan meningkatnya ekspor impor barang, serta melihat dari aspek ekonomi, manusia semakin tertarik untuk menggunakan jasa angkutan laut sebagai sarana transportasi yang dapat mengangkut barang dari suatu tempat ke tempat lain dengan aman dan efisien.

Untuk menunjang kelancaran pergerakan dan perjalanan kapal, diperlukan peralatan yang dapat mendukung pengoperasian kapal. Maka dari itu dibutuhkan pesawat-pesawat bantu diantaranya adalah ketel uap bantu yang berfungsi menghasilkan uap panas yang akan digunakan untuk memanaskan bahan bakar, memanaskan ruangan, memanaskan zat cair dalam tangki, memanaskan fresh water jacket cooling, memutar pompa turbin dan system lainnya.

Ketel uap bantu dituntut untuk selalu dapat menghasilkan uap panas yang mencukupi sesuai kebutuhan di atas kapal. Tersedianya uap panas merupakan hal yang mutlak bagi kelancaran operasional permesinan yang membutuhkan uap panas. Pelayaran dan pelayanan dapat terganggu jika penghasilan uap panas bermasalah, karena kurangnya pengetahuan cara pengoperasian yang aman dan benar sehingga auxiliary boiler mengalami gangguan atau mengalami kerusakan.

Penggunaan uap yang begitu banyak dibutuhkan di kapal, maka uap yang dihasilkan oleh ketel uap bantu haruslah memenuhi syarat produksi uap yang berkualitas yaitu dengan suhu tinggi dan produksi uap dalam jumlah banyak. Agar menghasilkan uap yang berkualitas dan 
dalam jumlah banyak maka dibutuhkan pembakaran yang sempurna pada ketel uap bantu.

Penelitian ini dilakukan di MT. Enduro, pada saat kapal sandar untuk bongkar muatan di Tanjung Uban, ketel uap yang seharusnya menghasilkan uap yang sekiranya dapat memenuhi kebutuhan saat bongkar muatan di mana uap yang seharusnya dihasilkan antara $10-25 \mathrm{~kg}$, pada saat itu steam yang dihasilkan hanya mencapai 8-12 kg sehingga hal itu mengakibatkan terhambatnya proses bongkar muatan dalam keadaan normal RPM pompa turbim dapat mencapai 1500 pada saat bongkar muatan di Tanjung Uban RPM pompa turbin hanya mencapai 700 .

Perumusan masalah penelitian adalah sebagai berikut :

1) Apakah yang menjadi faktor tidak optimalnya kerja auxiliary boiler dalam menghasilkan uap yang digunakan untuk proses bongkar muatan di MT. Enduro?

2) Apakah dampak yang terjadi ketika kurang optimalnya kerja dari auxiliary boiler dalam menghasilkan uap?

3) Bagaimana cara mengoptimalkan kerja dari auxiliary boiler untuk menghasilkan uap?

Untuk menghindari pembahasan yang melebar dalam penelitian ini penulis sengaja membatasi dengan masalah yang terjadi di kapal tempat taruni praktek yaitu di MT. Enduro. Penulis membatasi pembahasan penelitian ini hanya tentang faktor-faktor yang mempengaruhi tidak optimalnya pembakaran auxiliary boiler yang dapat menghambat proses bongkar muatan sesuai dengan tujuan penelitian. Penelitian tidak membahas hal-hal yang lebih spesifik dari ketel uap bantu.

Berikut adalah tujuan dalam pembuatan penelitian ini, yaitu:

1) Untuk mengetahui apa saja faktor yang mengakibatkan kurang optimalnya pembakaran pada auxiliary boiler yang dapat menghambat proses bongkar muatan di MT. Enduro.
2) Untuk mengetahui dampak yang terjadi ketika pembakaran auxiliary boiler tidak optimal dalam menghasilkan uap.

3) Untuk mengetahui cara mengoptimalkan kerja dari auxiliary boiler dalam menghasilkan uap.

\section{KAJAN PUSTAKA}

\section{A. Kajian Pustaka}

\section{1) Identifikasi}

Dalam buku Bakir dan

Suryanto (2006 : 217), "identifikasi adalah bukti diri, tanda kenal diri". Mengidentifikasikan (kata kerja) yaitu menentukan atau menetapkan identitas.

Menjelaskan bahwa indentifikasi adalah suatu cara yang dilakukan seseorang untuk mengambil alih ciriciri orang lain dan menjadikannya bagian yang terintegrasi dengan kepribadiannya sendiri. Dalam pengertiannya yang lain, adalah kecenderungan dalam diri individu untuk menjadi sama dengan individu lain. Individu yang menjadi sasaran identifikasi yaitu idola. Identifikasi berarti kegiatan yang dilakukan untuk mencermati, menentukan, menetapkan suatu tanda kenal diri atau bukti terhadap suatu objek yang diteliti.

\section{2) Pengertian auxiliary boiler}

Menurut tim penyusun pertamina Eropa Yogoslavia (1988: 12) dalam bukunya Pertamina Engine, bahwa pengertian auxiliary boiler adalah suatu pesawat atau mesin bantu yang berfungsi untuk menghasilkan uap sebagai keperluan di atas kapal, seperti pemanas bahan bakar, fresh water cooling, memutar pompa turbin, kebutuhan di deck dan untuk kebutuhan pesawat bantu lainnya. Auxiliary boiler di MT. Enduro berdiri sendiri, pada pembakarannya menggunakan boiler burning pump yaitu pompa untuk menyuplai bahan bakar pada auxiliary boiler. Boiler burning pump berdiri sendiri tidak menyatu pada sistem pembakaran main 
engine. Di kapal MT. Enduro sistem pembakarannya di furnance dengan segitiga api yaitu forced draught fan menyuplai udara ke dalam furnance sekaligus untuk membersihkan karbonkarbon yang ada di ruang pembakaran, sedangkan pilot burner terdapat elektroda untuk memercikkan api sebagai pembakaran awal menggunakan diesel oil pada main burner secara otomatis peneumatic pada pilot burner tertutup sehingga pembakaran menggunakan fuel oil pada main burner agar pembakaran merata, maka dibutuhkan tekanan udara kurang lebih $7 \mathrm{~kg}$ agar pemakaran dapat optimal. Dikarenakan di MT. Enduro burner horisontal sehingga membutuhkan tekanan udara yang cukup agar pembakaran merata pada dapur pembakaran dengan perbandingan udara dan bahan bakar \pm $7: 3$.

Sementara untuk ekonomiser di MT. Enduro menyatu dengan sistem gas buang pada main engine, pada saat kapal berlayar pada RPM 60, valve sirkulasi dibuka dan circulating pump dijalankan agar air di dalam auxiliary boiler dapat dialirkan ke ekonomiser untuk memproduksi steam untuk digunakan sebagai pemanas bahan bakar tanpa harus menyalakan auxiliary boiler.

\section{3) Fungsi auxiliary boiler}

Fungsi auxiliary boiler adalah untuk memproduksi uap yang akan digunakan dalam berbagai kebutuhan di atas kapal. Adapun fungsi uap yang dihasilkan dari produksi auxiliay boiler antara lain:

a. Sebagai media pemanas pada tangki-tangki bahan bakar

b. Sebagai media pemanas pada heater di kamar mesin

c. Sebagai penggerak pompa turbin untuk bongkar muatan

d. Sebagai pemanas air laut dalam proses pembutan air tawar

\section{4) Jenis-jenis boiler}

a. Ketel uap/boiler menurut fungsinya di kapal :

1. Ketel uap induk (main boiler) Yaitu ketel uap yang menghasilkan uap dan digunakan untuk menggerakkan mesin induk. Pada masa kini ketel-ketel yang digunakan sebagai ketel induk pada umumnya adalah ketel-ketel pipa air, seperti Foster Wheeler, babcock dan willcox.

2. Ketel uap bantu (auxiliary boiler) Yaitu ketel uap yang menghasilkan uap untuk keperluan pesawat bantu, seperti pompa-pompa dan pemanas. Jenis-jenis ketel uap bantu yang biasanya digunakan adalah ketel schots.

b. Ketel uap menurut struktur penyusunannya:

1. Ketel pipa api (fire tube boiler) Ketel pipa api adalah suatu ketel uap yang bekerja di mana nyala api dan gas-gas asap mengalir melalui pipa-pipa sedangkan air ketel mengalir didalamnya.

2. Ketel pipa air (water tube boiler) Ketel pipa air adalah suatu ketel uap yang bekerja di mana air berada di dalam pipa sedangkan pemanas dilakukan oleh gas-gas asap yang berada di sekeliling pipa-pipa tersebut atau pembentukan uap terjadi di dalam sejumlah pipa-pipa.

\section{5) Bagian-bagian auxiliary boiler}
a. Dapur pembakaran (furnace)
b. Nozzle
c. Manometer
d. Pesawat penduga
e. Economizer
f. Katup pengisia air ketel (water supply system)
g. Katup pengaman (safety valve).
h. Peralatan untuk membersihkan ketel uap
i. Drum air dan drum uap
j. Cerobong

6) Prinsip kerja auxilia boiler 
Prinsip kerja ketel uap cukup sederhana sama seperti pada saat kita sedang mendidihkan air menggunakan panci. Proses pendidihan air akan selalu diiringi proses perpindahan panas yang melibatkan bahan bakar, udara, material wadah air, serta air itu sendiri. Proses perpindahan panas mencakup tiga jenis perpindahan panas yang sudah sangat kita kenal yaitu konduksi, konveksi dan radiasi. Pada ketel pipa air misalnya, sumber panas didapatkan dari pembakaran bahan bakar di dalam furnance. Energi panas ini sebagian akan terpancar secara radiasi ke pipa-pipa sehingga memanaskan pipa-pipa tersebut. Panas yang terserap oleh permukaan pipa secara konduksi akan berpindah ke sisi permukaan dalam pipa. Di dalam pipa mengalir air yang terus menerus menyarap panas tersebut. Proses penyebaran panas antar molekul air di dalam aliran ini terjadi secara konvensi. Perpindahan panas konvensi antar molekul air, seakan-akan menciptakan aliran fluida tersendiri terlepas dengan aliran air di dalam pipa-pipa ketel. Gas hasil pembakar yang mengandung energi panas akan terus mengalir mengikuti bentuk auxiliary boiler hingga kesisi keluaran. Disepanjang perjalanan panas yang terkandung gas buang akan diserap oleh permukaan tubing auxiliary boiler dan diteruskan secara konduksi ke air di dalam pipa. Secara bertahap, air akan berubah fase menjadi uap basah (Saturatet steam) dan dapat berlanjut menjadi uap kering (superheated steam).

\section{7) Dasar-dasar perawatan auxiliary boiler}

Ketel uap tidak akan bertahan lama apabila tidak dilaksanakan pemeliharaan secara intensif, baik dalam masa operasi maupun dalam masa penyimpanan. Pemeliharaan secara seksama dalam masa operasi dimaksud adalah bagaimana cara mengoperasikan ketel uap tersebut sesuai petunjuk yang berlaku atau yang sesuai dengan design pembuatan auxiliary boiler tersebut. Di samping itu pula, maka penggunaan air umpan juga harus sesuai atau memenuhi syarat sebagai pengisian ketel. Yang jelas bahwa air pengisian auxiliary boiler harus bebas dari zat-zat yang dapat merusak auxiliary boiler, baik korosi maupun kerak. Untuk mencegah hal demikian, maka dilakukan perawatan externaltreatment dan internal treatment, misalnya dipasang ph control pada condensate line, atau dilakukan water treatment, juga penginjeksian chemical pada feed water dan boiler water.

\section{8) Burner}

Dalam buku veen (1977:78), sistem burner merupakan suatu sistem yang terdiri dari beberapa komponen, yang mana komponen-komponen tersebut satu dengan yang lain saling menunjang terhadap sistem kerja burner secara keseluruhan. Dalam hal ini harus ditunjang dengan kinerja komponen-komponen tersebut yang baik dan optimal agar pembakaran pada ketel uap dapat terlaksana.

\section{9) Brander}

Brander yaitu alat pengabut bahan bakar untuk pembakaran dalam lorong api, alat ini sudah merupakan satu unit yang sudah dilengkapi dengan blower, motor listrik, alat pengabut bahan bakar, pompa bahan bakar, alat penyalaan api. Alat ini diletakkan pada ujung muka lorong api.

\section{0) Pengertian pembakaran}

Dalam proses pembentukan uap faktor yang paling penting adalah proses pembakaran, menurut Tambunan (1984:31), pembakaran adalah suatu reaksi kimia dimana terjadi panas (nyala). Setiap proses pembakaran harus memerlukan udara pembakaran. Dari hasil pembakaran selain terjadi panas juga terjadi gas-gas di mana gas-gas asap ini akan dikeluarkan melalui cerobong. 
Proses pembakaran dapat terjadi bila konsentrasi antara uap bahan bakar dan oksigen terpenuhi dan terdapat energi panas yang cukup hal ini bisa disebut juga syarat segi tiga api harus terpenuhi. Proses terjadinya api (pembakaran) dikenal dengan nama segi tiga api, yaitu unsur bahan bakar, unsur udara (oksigen) dan energi panas. Bila ketiga unsur ini bertemu dan mencapai konsentrasi yang tepat, maka akan terjadi proses pembakaran, namun sebaliknya bila salah satu unsur dari tiga unsur tersebut ditiadakan maka proses pembakaran tidak akan terjadi.

\section{B. Definisi operasional}

1) Apendasi air

a. Cascade tank

yaitu suatu alat yang berfungsi untuk menyimpan air sebelum air dipompa ke dalam drum boiler

b. Feed pump

yaitu suatu alat yang berfungsi untuk mengalirkan air berasal dari cascade tank menuju ke drum boiler untuk dipanaskan dan diuapkan.

c. Pesawat penduga (kaca penduga) yaitu alat untuk mengetahui tinggi rendahnya level air dalam drum ketel, alat ini dihubungkan dengan dua batang pipa yaitu yang satu dihubungkan pada bagian tangki yang berisi air dan yang lainnya pada tangki yang berisi uap.

2) Apendasi uap

\section{a. Main valve}

Adalah sebuah katup utama yang berfungsi mengalirkan uap dari drum ketel ke seluruh sistem di dalam kapal.

b. Katup pengaman (safety valve) yaitu alat untuk mencegah terjadinya tekanan yang terlalu tinggi diatas tekanan yang diperbolehkan, yakni dengan membuka katup secara otomatis atau tidak otomatis, sehingga uap dapat dikeluarkan maka tekanan akan turun.

\section{c. Manometer \\ yaitu alat pengukur tekanan uap umumnya manometer yang digunakan adalah manometer Bourdon}

\section{METODOLOGI PENELITIAN}

\section{A. Kerangka Pikir}

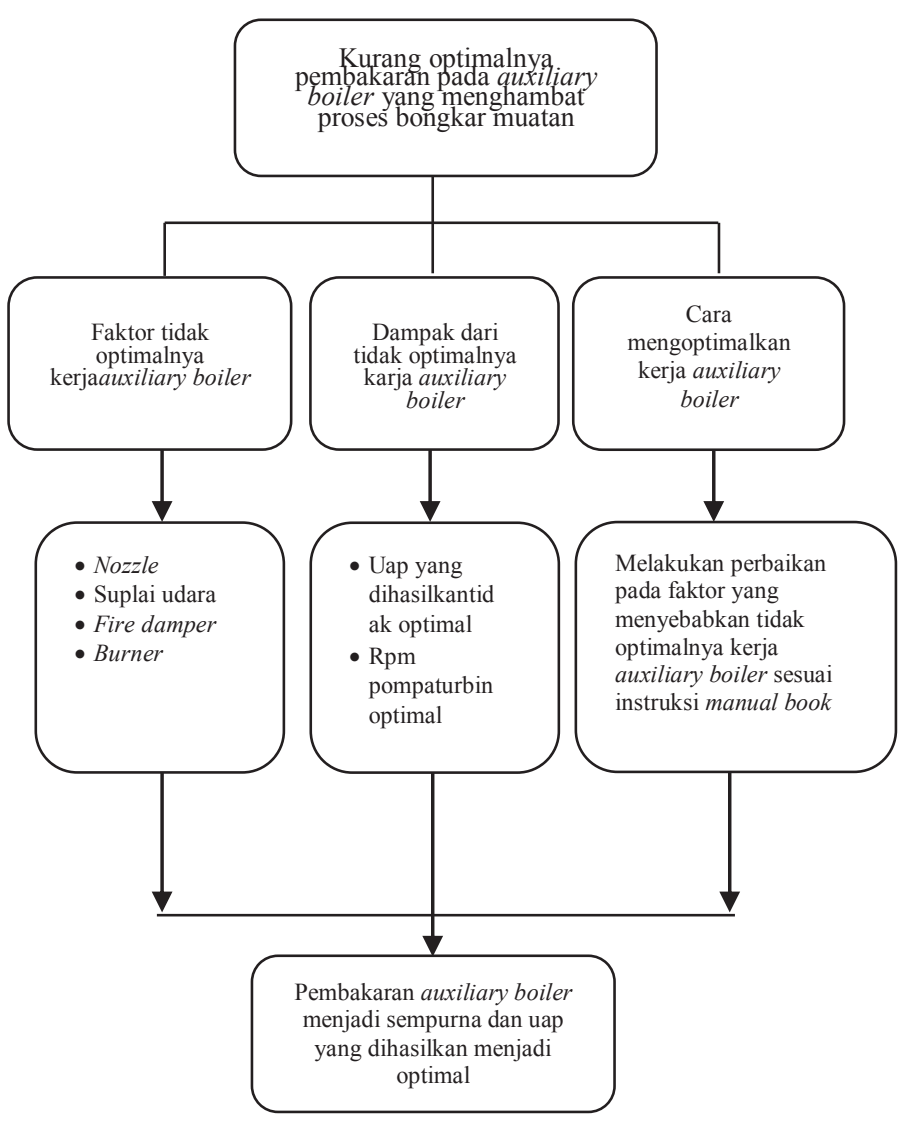

Dalam kerangka pikir yang penulis sajikan membahas mengenai kurang optimalnya pembakaran pada auxiliary boiler yang menghambat proses bongkar muatan. Untuk membahas penelitian ini secara teratur maka penulis menulis kerangka pikir agar penelitian berjalan secara sitematis dan terpadu, kerangka pikir yang penulis tulis meliputi kejadian yang terjadi di lapangan dengan segala permasalahan yang diangkat sebagai bahan penelitian.

Metode penelitian yang digunakan oleh peneliti di dalam menyampaikan masalah adalah deskriptif kualitatif untuk menggambarkan dan menguraikan objek yang diteliti. Metode ini dilakukan dengan 
cara mengumpulkan data yang telah diperoleh dan dianalisa untuk dihubungkan dengan teori-teori yang ada untuk diambil kesimpulan yang logis.

Adapun yang dimaksud deskriptif menurut MOLEONG (2001:6) deskriptif adalah data yang dikumpulkan berupa katakata, gambar dan bukan angka-angka. Laporan penelitian akan berisi kutipankutipan data untuk memberi gambaran penyajian laporan, data tersebut mungkin berasal dari naskah wawancara, catatan lapangan, foto, dokumen pribadi, catatan atau memo, dan dokumen resmi lainnya. Dan deskriptif adalah suatu bentuk penelitian yang ditujukan untuk mendepenelitiankan fenomena-fenomena yang ada, baik fenomena alamiah maupun fenomena buatan manusia. Fenomena itu bisa berupa bentuk, aktivitas, karakteritik, perubahan, hubungan dan perbedaan antara fenomena yang satu dengan fenomena yang lainnya.

Jadi kualitatif adalah penelitian yang berdasarkan pada filsafat post positisme, digunakan untuk meneliti pada kondisi obyek yang alamiah, (sebagai lawannya adalah eksperimen) di mana peneliti adalah sebagai instrumen kunci, pengambilan sampel sumber data dilakukan secara purposive dan snow baal, teknik pengumpulan dengan trianggulasi (gabungan) analisis data bersifat induktif/kualiatif, dan hasil penelitian kualitatif lebih menekankan makna daripada generalisasi dan kualitatif adalah keterkaitan spesifik pada studi hubungan sosial yang berhubungan dengan fakta dari pluralisasi dunia kehidupan. Metode ini diterapkan untuk melihat dan memahami subjek, dan objek penelitian yang meliputi orang, lembaga yang berdasarkan fakta yang tampil secara apa adanya.

Lokasi penelitian dan pengamatan tentang pesawat auxiliary boiler dilakukan saat penulis melaksanakan praktek laut pada Agustus 2014 sampai Agustus 2015 di kapal MT. Enduro.

Adapun sumber data yang diperlukan dan dipergunakan dalam penyusunan penelitian ini merupakan informasi yang diperoleh penulis melalui pengamatan langsung dan wawancara Dari sumber-sumber ini diperoleh data sebagai berikut :

1) Data Primer

Data primer adalah suatu data yang merupakan perolehan secara langsung dari sumbernya dan dilakukan pencatatan. Dalam hal ini penulis memperoleh data primer secara langsung dari hasil wawancara dengan pihak yang terkait yaitu para perwira kapal tersebut serta para awak kapal bagian. Penulis memperoleh data dari diskusi dengan Masinis III, yang bertanggung jawab langsung terhadap pesawat auxiliaryboiler tersebut, dan dengan masinis lain yang lebih tahu tentang permasalahan-permasalahan pada auxiliary boiler di kapal. MT. Enduro.

2) Data Sekunder

Data Sekunder adalah suatu data yang merupakan pengusahaan sendiri mengumpulkan data oleh penulis, selain dari sumbernya yang diteliti. Data ini diperoleh dari buku-buku yang berkaitan dengan obyek penelitian penelitian atau yang berhubungan dengan masalah yang akan dibahas, yang diperlukan sebagai pedoman teoritis dan ketentuan formal dari keadaan nyata dalam melakukan observasi. Serta informasi lain yang didapat penulis dari kapal-kapal lain yang mungkin menggunakan pesawat yang sama jenisnya sehingga penulis memperoleh masukan.

Berdasarkan latar belakang dan perumusan masalah yang penulis lakukan sebelumnya, maka dalam menyusun penelitian ini dibutuhkan suatu pengamatan. Sehingga mampu mendapatkan data yang benar, agar tujuan penulisan dapat tercapai dan sesuai dengan judul yang penulis ambil. Di sini penulis menggunakan beberapa metode dalam menyususn penelitian ini. Adapun metode pengumpulan data yang penulis pergunakan yaitu :

1. Metode observasi 
Observasi adalah metode di mana peneliti melakukan pengamatan dan pencatatan secara sistematis terhadap gejala atau fenomena yang diselidiki. Mengumpulkan data secara langsung mengenai gejalagejala tertentu dengan melakukan pengamatan serta mencatat data yang berkaitan dengan pokok masalah yang akan diteliti. Dengan mengadakan pengamatan secara langsung sewaktu penulis melaksanakan penelitian di MT. Enduro. Di samping itu observasi adalah alat pengumpulan data secara langsung dan sangat penting dalam penelitian deskriftif.

2. Metode wawancara

Wawancara adalah metode pengumpulan informasi dengan cara mengajukan sejumlah pertanyaan lisan, untuk dijawab secara lisan pula. Metode wawancara ini sangat efektif untuk mendapatkan penjelasan yang lebih rinci mengenai pertanyaan-pertanyaan atau banyak hal yang tidak dipahami dalam hal permasalahan yang berhubungan dengan topik yang akan dibahas, yaitu tentang auxiliary boiler beserta permasalahannya. Wawancara ini dilakukan oleh penulis pada jam kerja atau pada waktu senggang secara berdiskusi.

3. Metode studi pustaka

Kepustakaan juga merupakan metode pelengkap di dalam teknik pengumpulan data. Metode kepustakaan digunakan dengan maksud untuk mendapatkan atau mengumpulkan data dengan jalan mempelajari buku-buku yang berkaitan dengan pokok masalah yang akan diteliti. Metode kepustakaan ini digunakan juga sebagai pelengkap data apabila terdapat kesulitan dalam pemecahan masalah dalam penelitian dengan mempelajari teori-teori yang berhubungan dengan pokok masalah. Metode ini juga memanfaatkan buku-buku referens (manual book) yang berada di atas kapal yang berhubungan dengan obyek yang sedang diteliti oleh penulis
Analisis data merupakan bagian yang sangat penting dalam penelitian karena dari analisis ini akan memperoleh temuan baik temuan substantif maupun formal. Selain itu, analisis data kualitatif sangat sulit karena tidak ada pedoman buku, tidak berproses secara linier, dan tidak ada aturan-aturan yang sistematis. Pada hakikatnya, analisis data adalah sebuah kegiatan untuk mengatur, mengurutkan, mengelompokkan, memberi kode/tanda, dan mengkategorikannya sehingga diperoleh suatu temuan berdasarkan fokus atau masalah yang ingin dijawab. Melalui serangkaian aktivitas tersebut, data kualitatif yang biasanya berserakan dan bertumpuk-tumpuk bisa disederhanakan untuk akhirnya bisa dipahami dengan mudah. Analisis data kualitatif sudah dimulai saat peneliti mulai mengumpulkan data, dengan cara memilah mana data yang sesungguhnya penting atau tidak. Ukuran penting dan tidaknya mengacu pada konstribusi data tersebut pada upaya menjawab fokus penelitian

\section{1) Reduksi Data}

Dalam buku Sugiyono (2009:247)

"mereduksi data berarti merangkum, memilih hal-hal yang pokok, memfokuskan pada hal-hal yang penting, dicari pola dan temanya. Dengan demikian data yang telah direduksi akan memberikan gambaran yang lebih jelas, dan mempermudah peneliti untuk melakukan pengumpulan data selanjutnya, dan mencarinya bila diperlukan".

2) Penyajian Data

Sugiyono (2009:249) “dalam penelitian kualitatif, penyajian data bisa dilakukan dalam bentuk uraian singkat, bagan, hubungan antar kategori dan sejenisnya. Dengan mendisplaikan data, maka akan memudahkan untuk memahami apa yang terjadi, merencanakan kerja selanjutnya berdasarkan apa yang telah dipahami tersebut".

3) Menarik Kesimpulan

Menarik Kesimpulan merupakan kemampuan Penulis dalam menyimpulkan berbagai temuan data yang diperoleh selama proses penelitian berlangsung. 
Lebih lanjut analisa data kualitatif merupakan upaya yang berlanjut, berurutan dan terus menerus. Masalah reduksi data, penyajian data dan penarikan kesimpulan (verifikasi) menjadi gambaran keberhasilan secara berurutan sebagai rangkaian kegiatan analisa yang saling susul menyusul. Pada penelitian ini digunakan analisa data yang bersifat terbuka. Dikatakan terbuka karena terbuka bagi perubahan perbaikan dan penyempurnaan berdasarkan data baru yang masuk

\section{HASIL PENELITIAN DAN PEMBAHASAN}

\section{A. Gambaran umum obyek yang diteliti}

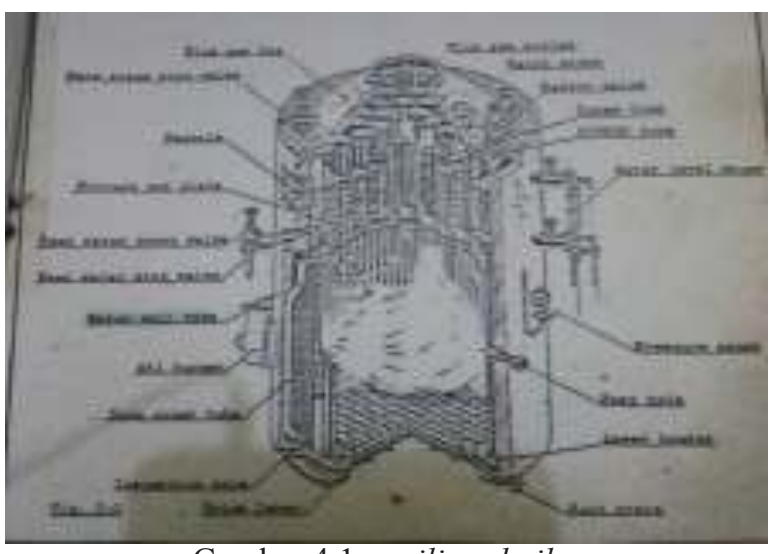

Gambar 4.1 auxiliary boiler

Auxiliary boiler adalah salah satu permesinan bantu di kapal yang digunakan sebagai alat penghasil uap. Uap yang dihasilkan dari auxiliary boiler tersebut nantinya akan digunakan sebagai pemanas bahan bakar, pemanas fresh water cooling, menggerakkan pompa turbin, memanaskan tangki-tangki muatan dan untuk kebutuhan sistem lainnya. Kelancaran pengoperasian auxiliary boiler tidak mungkin terjadi tanpa campur tangan atau perhatian dari semua crew kamar mesin, untuk menunjang kelancaran dalam pengoperasian auxiliary boiler maka dalam hal ini dilakukan perawatan yang benar yaitu perawatan yang sesuai dengan instruksi dari manual book dan juga pemeriksaan terhadap kondisi dari keadaan auxiliary boiler itu sendiri

\section{B. Analisa hasil penelitian}

Analisa hasil penelitian merupakan pemaparan tentang masalah-masalah yang ditemukan dalam sebuah penelitian yang dilakukan di MT. Enduro selama kurang lebih satu tahun taruni melakukan praktek laut. Hasil analisa tersebut menguraikan atau menjelaskan perumusan masalah pada penelitian pesawat bantu auxiliary boiler. Dengan melalui identifikasi didapatkan masalah-masalah yang pada akhirnya akan dibahas pada pembahasan masalah. Didalamnya berisikan penyebab timbulnya masalah, dan dampak dari masalah sekaligus untuk mencari bagaimana penanggulangan dari masalah tersebut dan dapat kita jadikan pelajaran agar tidak terjadi hal yang dapat mengganggu pengoperasian kelancaran kapal.

Pada saat terjadi pembakaran burner berpengaruh penting terhadap nyala api dalam auxiliary boiler. Pada saat penulis melakukan bongkar muatan penulis menemukan masalah yaitu kurang optimalnya pembakaran pada auxiliary boiler, setelah kejadian tersebut terjadi Masinis III melakukan pemeriksaan pada pesawat bantu tersebut, pada saat pemeriksaan masinis III menemukan hal yang janggal pada ujung nozzle dari burner dikarenakan pada ujung nozzle tersebut banyak lelehan fuel oil. Tindakan yang dilakukan adalah pembersihan burner berserta nozzle dengan mengunakan kerosene setelah pembersihan selesai masinis III mencoba menyalakan auxiliary boier kembali tetapi pembakaran tetap tidak optimal. Hal tersebut dilakukan penanganan beserta pemeriksaan secara menyeluruh pada pesawat auxiliary boiler.

Penyebab dari kurang optimalnya pembakaran pada auxiliary boiler di MT. Enduro disebabkan oleh kinerja pengabutan nozzle burner yang kurang optimal di mana nozzle sering tersumbat oleh kotorankotoran dari bahan bakar, karena bahan bakar yang masuk pada nozzle tidak melalu proses pemisahan terlebih dahulu di dalam purifier karena purifier di kapal MT. Enduro tidak 
bisa dioperasikan sehingga burner sering tersumbat. Purifier adalah permesinan yang berfungsi untuk memisahkan kotoran dengan minyak.

Pada waktu pemeriksaan masinis III menemukan faktor-faktor penyebab terjadinya pembakaran yang tidak optimal pada auxiliary boiler dan pada bagian ini penulis selain membahas faktor faktor penyebab tidak optimalnya pembakaran pada auxiliary boiler, dampak dari tidak optimalnya pembakaran dan bagaimana cara mengatasi masalah tersebut yaitu :

1) Faktor-faktor yang menyebabkan tidak optimalnya kinerja pada auxilary boiler antara lain :

a. Tidak sempurnanya pembakaran pada auxiliary boiler yang diakibatkan oleh beberapa faktor yaitu temperatur bahan bakar yang tidak sesuai, yang disebabkan kerusakan pada electrik heater yang rusak atau putus.

b. Kurangnya suplai udara pada auxiliary boiler disebabkan karena berkurangnya putaran pada elektro motor sehingga tidak bisa bekerja secara maksimal.

c. Macetnya fire damper saat mensuplai udara hal ini dikarenakan oleh rusaknya atau sudah lemahnya magnet contactor sehingga tidak kuat saat harus menggerakkan fire damper.

d. Burner adalah salah satu alat pengabut bahan bakar pada auxiliary boiler. Di dalam burner terdapat nozzle burner yang fungsinya agar bahan bakar yang masuk ke dalam dapur pembakaran dapat berbentuk spray sehingga pembakaran dalam dapur pembakaran dapat merata. Oleh sebab itu burner harus selalu dicek agar tidak tersumbat oleh kotoran dan dapat mengabutkan bahan bakar secara optimal sehingga pembakaran menjadi sempurna.

2) Dampak yang terjadi dari tidak optimalnya pembakaran pada auxiliary boiler antara lain: a. Steam/uap yang dihasilkan tidak maksima

Ketidakmaksimalan steam/uap disebabkan karena pembakaran auxiliary boiler yang tidak sempurna sehingga kebutuhan uap/steam di atas kapal tidak memenuhi kebutuhan yang diperlukan karena kebutuhan uap di kapal cukup banyak.

b. RPM pompa turbin tidak maksimal Ketidakmaksimalan RPM pompa turbin disebabkan karena kurangnya uap/steam yang dihasikan oleh pembakaran auxiliary boiler.

3) Cara mengatasi penyebab tidak optimalnya pembakaran pada auxiliary boiler antara lain :

a. Temperatur bahan bakar yang tidak sesuai

Melakukan perbaikan pada elektrik heaternya dan mengatur temperatur bahan bakar sesuai dengan instruksi manual book.

b. Kurangnya suplai udara Melakukan perbaikan pada elektro motornya dan melakukan penggantian ball bearing, sesuai dengan part nomer yang ada di manual book.

c. Macetnya fire amper

Melakukan perbaikan pada magnet contaktornya karena kalau sudah terlalu lama magnet contaktornya tidak bisa untuk menggerakkan fire damper melakukan perbaikan dan penggantian magnet contaktornya sesuai dengan manual book.

d. Burner

Melakukan pengecekan terhadap nozzle burner dan melakukan penggantian nozzle burner sesuai dengan manual book

\section{Pembahasan masalah}

1. Faktor-faktor yang menyebabkan tidak optimalnya pembakaran pada auxiliary boiler?

a) Tidak sempurnanya pembakaran pada auxiliary boiler 
Temperatur bahan bakar yang cukup atau tepat sangat diperlukan untuk menjaga agar viskositas bahan bakar dapat dikabutkan dengan baik yaitu $180{ }^{\circ} \mathrm{C}$. Pada saat penulis melaksanakan praktek laut di MT. Enduro, penulis menemukan ketidaksesuaian temperatur bahan bakar yang mengakibatkan tidak sempurnanya pembakaran pada auxiliary boiler.

Pada saat dilakukan pemeriksaan terhadap bahan bakar ketel uap maka kami mendapatkan data sebagai berikut:

Tabel 4.1 : Temperatur ketel uap

\begin{tabular}{|c|c|c|}
\hline $\begin{array}{c}\text { Temperatur } \\
\text { seharusnya }\end{array}$ & $\begin{array}{c}\text { Temperatur } \\
\text { yang terjadi }\end{array}$ & Keterangan \\
\hline $60^{\circ}-85^{\circ} \mathrm{C}$ & $55^{\circ} \mathrm{C}$ & Abnormal \\
\hline
\end{tabular}

Dari data di atas maka sangat jelas bahwa terjadi selisih $5^{\circ} \mathrm{C}$ untuk menunjang pembakaran yang baik pada ketel uap. Temperatur yang dapat menyebabkan kegagalan pembakaran pada ketel uap adalah lebih kecil dari $60^{\circ} \mathrm{C}$ dan temperatur di atas $85^{\circ} \mathrm{C}$. Hal ini berkaitan dengan kondisi heater bahan bakar. Heater yang digunakan di MT. Enduro adalah jenis steam heater yaitu media pemanasnya adalah steam sebagai pemanas.

b) Kurangnya suplai udara Udara merupakan salah satu bahan yang menunjang terjadinya suatu pembakaran pada auxiliary boiler dan udara yang masuk ke furnance harus berbanding dengan bahan bakar yang masuk ke furnance, maka dari itu diperlukan adanya pemeriksaan secara berkala pada elekrik motornya. Pada saat putaran elektrik motor menurun dari putaran normalnya yaitu 3480 rpm menghasilkan tekanan $1.25 \mathrm{~kg}$ putarannya turun menjadi sekitar 1200rpm menghasilkan tekanan $0.35 \mathrm{~kg}-0.70 \mathrm{~kg}$, maka putaran fan juga ikut menurun sehingga suplai udara untuk pembakaranpun ikut menurun. Jika suplai udara berkurang maka pembakaran tidak berjalan dengan sempurna. Pada saat penulis melaksanakan praktek laut, penyebab turunnya putaran elektrik motor adalah karena komponen pada ball bearing rusak sehingga putaran menjadi berat. Pada saat putaran elektrik motor menurun maka akan berdampak pada kurangnya suplai udara untuk pembakaran, karena besar kecilnya suplai udara yang didapat berdasarkan cepat lambatnya putaran fan yang diputar oleh elektrik motor. Jika putaran fan menurun maka akan berakibat pada kurangnya suplai udara untuk pembakaran sehingga pembakaran berjalan dengan tidak sempurna.

c) Macetnya fire damper

Damper berfungsi untuk mengatur suplai udara pembakaran yang masuk ke dalam dapur pembakaran auxiliary boiler. Hal ini dimaksudkan agar suplai udara pembakaran dapat terkontrol sehingga pembakaran berjalan dengan sempurna yaitu 1,25 kg sedangkan yang terjadi di MT. Enduro udara yang masuk ke dalam dapur pembakaran yaitu antara 0,35 $0,70 \mathrm{~kg}$ sehingga terjadi pembakaran yang tidak sempurna. Namun pada saat penulis melakukan praktek laut penulis menemukan masalah yaitu macetnya damper tersesbut yang diakibatkan oleh rusaknya atau sudah lamanya magnet contactor sehingga tidak mampu lagi menggerakkan damper saat suplai udara. Hal ini berpengaruh kurangnya supalai udara yang masuk dalam pembakaran yang mengakibatkan pembakaran yang tidak sempurna.

d) Burner

Burner merupakan komponen utama pembakaran pada auxiliary boiler yang berfungsi sebagai tempat pengabutan bahan bakar utama yang 
kemudian bercampur dengan udara yang terbakar oleh api yang diproduksi oleh ignition burner. Di dalam burner terdapat nozzle burner yang mana nozzle burner tersebut harus selalu dijaga dan dichek apakah:

1) Nozzle burner kotor Nozzel burner berfungsi sebagai alat pengabut bahan bakar agar pembakaran tetap berjalan dengan lancar sehingga menghasilkan panas dan uap yang baik.

Berdasarkan pengalaman penulis pada saat melaksanakan praktek laut, penulis menemukan nozzle burner kotor akibat bahan bakar yang tidak disaring terlebih dahulu di dalam purifier dan kotorankotoran tersebut mengendap pada burner pada saat melakukan pembersihan burner ditemukan kotoran yang cukup banyak pada burner.

2) Jarak elektrode pilot burner tidak tepat

Elektrode pada pilotburner berfungsi sebagai pengapian awal. Jarak elektrode pilot burner harus sesuai dengan jarak yang sudah ditentukan pada instruction manual book. Apabila jarak elektrode dengan pilot burner tidak sesuai maka akan berpengaruh terhadap panjang lidah api. Lidah api akan menjadi pendek sehingga dapat terjadi kegagalan pembakaran.

Tabel 4.2 : Jarak elektrode pilot burner

\begin{tabular}{|c|c|c|}
\multicolumn{3}{c}{ normal } \\
$\begin{array}{c}\text { Jarak elektrode } \\
\text { pada manual } \\
\text { book }\end{array}$ & $\begin{array}{c}\text { Jarak } \\
\text { elektrode } \\
\text { yang terjadi }\end{array}$ & Keterangan \\
\hline $8 \mathrm{~mm}$ & $5 \mathrm{~mm}$ & Abnormal \\
\hline
\end{tabular}

Dari data di atas maka sangat jelas bahwa terjadi ketidaksesuaian jarak elektrode sehingga terjadi kegagalan pembakaran sehingga mengakibatkan pembakaran tidak sempurna.

3) Bocor atau menetesnya fuel oil dari nozzle

Nozzel berfungsi sebagai pengabut bahan bakar yang dapat menjaga pembakaran agar tetap konstan sehingga menghasilkan panas dan uap yang baik. Namun pada saat penulis melakukan praktek laut penulis menemukan masalah yaitu kebocoran pada nozzle yang diakibatkan oleh melebarnya lubang pada ujung nozzle yang disebabkan lamanya pemakian nozzle tersebut. Selain pada bagian ujung nozzle juga ditemukan rembesan pada bagian nozzle holder yang melalui ulir nozzle holder hal ini mengakibatkan terjadinya penumpukan fuel oil pada burning chamber

4) Mengendapnya fuel oil didalam burning chamber

Burning chamber adalah suatu tempat yang berfungsi sebagai ruang pembakaran pada auxiliary boiler yang mana seharusnya di dalam burning chamber tidak boleh ada tetesan fuel oil. Namun pada saat penulis melaksanakan praktek laut penulis menemukan masalah yaitu mengendapnya fuel oil pada burning chamber yang diakibatkan oleh bocor dan menetesnya fuel oil yang terjadi diantara ulirdengan nozzle holder pada burner, saat burner melakukan pengabutan bahan bakar pada saat itu bahan bakar tidak bisa mengabut secara sempurna sehingga menetes dan kemudian menumpuk pada burning chamber yang mengakibatkan pembakaran yang tidak sempurna pada auxiliary boiler.

\section{4) Apakah dampak yang terjadi ketika} kurang optimalnya kerja dari 


\author{
auxiliary boiler dalam menghasilkan \\ uap?
}

a. Uap yang dihasilkan tidak optimal Uap adalah titik-titik dari benda cair yang mana uap yang dibutuhkan di atas kapal cukup banyak, sedangkan Uap yang dihasilkan oleh pembakaran auxiliary boiler tidak optimal uap yang awalnya antara 20-25kg dalam keadaan normal, pada saat terjadi ketidakoptimalan pembakaran pada auxiliary boiler uap yang dihasilkan kurang lebih $10-13 \mathrm{~kg}$ sehingga uap yang dihasilkan tidak memenuhi kebutuhan di atas kapal sedangkan kebutuhan uap di atas kapal cukup banyak

b. RPM pompa turbin tidak optimal Turbin adalah rotary engine (mesin yang berotasi) yang dapat mengekstrak energi dari aliran fluida yang mana seharusnya pompa turbin harus selalu bekerja maksimal. Pada saat penulis menemui masalah terhadap pompa turbin yang mana kinerja dari pompa turbin/ RPM pompa turbin tidak maksimal pompa turbin yang seharusnya bisa menghasilkan RPM kurang lebih 1500 dalam keadaan normal pada saat itu pompa turbin hanya bisa menghasilkan RPM 700

\section{5) Bagaimana cara mengoptimalkan kerja dari auxiliary boiler untuk menghasilkan uap?}

a) Temperatur bahan bakar tidak sesuai Agar temperatur bahan bakar sesuai maka langkah yang diambil yaitu sebagai berikut:

1. Melakukan perbaikan pada electric heaternya

2. Mengatur temperatur bahan bakar sesuai dengan instruction manual book pada fuel oil temperature control

3. Selalu melakukan pengecekan terhadap temperatur bahan bakar pada fuel oil temperature control
4. Cek viscositas bahan bakar sesuai dengan instruction maunal book

b) Kurangnya suplai udara

Untuk mengatasi kurangnya suplai udara yang masuk ke dalam dapur pembakaran dapat dilakukan pengecekan pada elekro motornya bila terjadi kerusakan pada elektro motornya lakukan perbaikan pada elektro motor tersebut seperti yang terjadi di kapal MT. Enduro yang mana terjadi kerusakan pada ball bearingnya maka ball bearing tersebut harus diganti dengan yang baru.

c) Macetnya fan damper saat mensuplai udara

Untuk mengatasi hal tersebut dilakukan perbaikan/pengantian pada magnet contactor serta melakukan perawatan terhadap damper sesuai dengan instruksi manual book agar supaya pada saat damper melakukan suplai udara pada saat pembakaran bisa berjalan dengan normal sehingga antara udara dan bahan bakar yang masuk ke dalam dapur pembakaran seimbang dan pembakaran menjadi sempurna.

Untuk mencegah agar tidak terjadi kemacetan pada fan damper maka diperlukan adanya perawatan pada fan damper tersebut.

d) Burner

Untuk mengatasi permasalahan yang terjadi pada burner yaitu dengan cara melakukan pembersihan pada burner dengan cara disikat menggunakan sikat khusus untuk burner bila sudah tidak biasa digunakan ganti dengan yang baru.

1) Nozzle burner kotor

Hal yang dilakukan apabila nozzle burner kotor adalah dengan membersihkan atau mengganti nozzle burner dengan nozzle burner yang baru jika diperlukan 
dan mengecek filter bahan bakar masih bagus apa tidak bila filter bahan bakar sudah rusak segera lakukan penggantian karena bila tidak diganti, dikhwatirkan filter tersebut tidak bisa bekerja dengan baik sehingga menyebabkan nozzle burner cepat kotor/ tersubat sehingga tidak bisa mengabutkan bahan bakar dengan baik dan dapat menyebabkan tidak sempurnanya pembakaran pada auxiliary boiler, karena salah satu yang menjadi penyebab pembakaran sempurna atau tidaknya adalah pengabutan bahan bakar yang dikabutkan oleh nozzleburner, karena Nozzle burner sangat berperan penting dalam pembakaran.

2) Jarak electrode dengan pilot burner

Menurut manual book jarak elektrode dengan pilot burner adalah $8 \mathrm{~mm}$, sedangkan yang terjadi di kapal MT. Enduro adalah $5 \mathrm{~mm}$, hal ini mempengaruhi panjang lidah api akan menjadi pendek dan igniter yang tidak bisa memercikan api sehingga mengakibatkan kegagalan dalam pembakaran awal. Untuk mengatasi hal tersebut diperlukan pemeriksaan dan perawatan secara rutin terhadap jarak elektrode dengan pilot burner agar pilot burner dapat bekerja dengan baik sehingga tidak ada kegagalan dalam pembakaran dan pembakaran menjadi sempurna.

3) Bocor atau menetesnya fuel oil dari nozzle burner

Bocor serta menetesnya fuel oil pada nozzle dipengaruhi oleh rusaknya ulir yang terhubung dari nozzle ke nozzle holder yang sudah terlalu lama serta keausan pada ulir tersebut sehingga tidak bisa mengikat nozzle dengan kuat dan pada ujung nozzle terdapat kerusakan melebarnya lubang pada ujung nozzle dikarenakan usia pemakaian yang sudah lama dan terdapatnya kerak pada lubang nozzle yang dibersihkan dengan cara yang salah sehingga mengakibatkan lubang pada ujung nozzle rusak / melebar sehingga saat burner mengabutkan bahan bakar tidak dapat mengabutkan fuel oil secara maksimal sehingga fuel oil jatuh kedalam burning chamber.

4) Mengendapnya fuel oil pada burning chamber

Burning chamber adalah suatu tempat yang berfungsi sebagai ruang pembakaran pada pesawat auxiliaryboiler, di dalam burning chamber tidak boleh ada tetesan fuel oil didalamnya karena tetesan fuel oil tersebut lama kelamaan akan menyebabkan korosi pada burning chamber. Namun pada saat penulis melaksanakan praktek laut penulis menemukan masalah yaitu mengendapnya fuel oil pada burning chamber yang diakibatkan oleh bocor dan menetesnya fuel oil dari burner saat burner melakukan pengabutan bahan bakar, sehingga menumpuk pada burning chamber yang mengakibatkan pembakaran tidak sempurna pada auxiliay boiler. Untuk mengatasi hal tersebut dilakukan pembersihan pada chamber dengan menggunakan minyak diesel oil atau chemical dengan menyeluruh sampai bersih supaya pada saat terjadi pembakaran bisa berjalan dengan normal karena fuel oil yang menumpuk pada chamber tidak ikut terbakar.

\section{KESIMPULAN}

Dari uraian yang telah dikemukakan pada bab pembahasan, maka dapat disimpulkan beberapa faktor yang dapat mempengaruhi 
terhadap pembakaran yang tidak sempurna pada auxiliary boiler adalah:

1. Faktor penyebab pembakaran yang tidak sempurna pada auxiliary boiler dipengaruhi oleh:

a. Temperatur bahan bakar yang tidak sesuai dikarenakan temperatur bahan bakar yang masuk ke dalam heater yaitu $55^{\circ} \mathrm{C}$, sedangkan temperatur bahan bakar menurut instruction manual book yaitu $60^{\circ} \mathrm{C}-85^{\circ} \mathrm{C}$ untuk mencapai pembakaran yang sempurna.

b. Kurangnya suplai udara yang disebabkan turunnya putaran electric motor pada primary air fan yang normalnya 3480 rpm menghasilkan $1,25 \mathrm{~kg}$ turun menjadi $1200 \mathrm{rpm}$ menghasilkan 0,35-0,70 $\mathrm{kg}$ sehingga menyebabkan pembakaran pada auxiliary boiler menjadi tidak sempurna.

c. Fire damper yang macet akibat rusaknya atau sudah lemahnya magnet contactor, sehingga pada saat fire damper akan melakukan pengaturan udara magnet contactor tidak kuat untuk menggerakkan fire damper.

d. Nozzle burner yang kotor disebabkan oleh bahan bakar yang masuk ke dalam nozzle burner tidak melalu proses pemisahan terlebih dahulu didalam purifier sehingga pengabutan bahan bakar tidak sempurna karena adanya endapan karbon pada nozzle burner, Jarak elektrode dengan pilot burner yang tidak tepat yang normalnya $8 \mathrm{~mm}$ menjadi $5 \mathrm{~mm}$ sehingga menyababkan kegagalan pada saat awal pembakaran, bocor atau menetesnya fuel oil dari nozzle yang disebabkan oleh melebarnya lubang pada ujung nozzle karena lamanya pemakaian nozzle sehingga menyebabkan bahan bakar mengendap di dalam burning chamber, mengendapnya fuel oil pada burning chamber mengakibatkan fuel oil ikut terbakar pada saat proses pembakaran auxiliary boiler hal tersebut yang menyebabkan tidak optimalnya pembakaran pada auxiliary boiler.
2. Dampak yang terjadi dari tidak optimalnya pembakaran pada auxiliary boiler adalah

a. Uap yang dihasikan tidak maksimal tekanan uap yang normalnya antara 20$25 \mathrm{~kg}$ menjadi $10-13 \mathrm{~kg}$ sehingga tidak memenuhi kebutuhan di atas kapal sedangkan kebutuhan uap di atas kapal cukup banyak.

b. Rpm pompa turbin tidak maksimal, yang normalnya RPM pompa turbin mencapai 1200 sedangkan pada saat terjadi ketidakoptimalan pembakaran pada auxiliary boiler RPM yang dihasilkan hanya mencapai 700 .

\section{Cara mengoptimalkan pembakaran pada auxiliary boiler adalah}

a. Untuk mengatasi temperatur bahan bakar yang tidak sesuai yaitu dengan cara melakukan perbaikan pada heater bahan bakar, cek viskositas bahan bakar dan mengatur temperatur bahan bakar sesuai dengan instruction manual book.

b. Untuk mengatasi kurangnya suplai udara dengan cara melakukan pengecekan pada elektro motor, bila terjadi kerusakan pada salah satu komponennya, maka komponen tersebut harus diganti dengan komponen yang sama sesuai dengan instruction manual book.

c. Untuk mengatasi macetnya fire damper yaitu dengan cara mengganti magnetic contactornya dan melakukan perawatan secara berkala sesuai dengan instruksi manual book.

d. Untuk mengatasi nozzle burner yang kotor yaitu dengan cara melakukan pembersihan, penggantian pada nozzle dan melakukan perawatan secara rutin pada nozzle burner sesuai instruksi manual book. 


\section{DAFTAR PUSTAKA}

Bakir R, Suyoto dan Sigit Suryanto. 2006.

Kamus Bahasa Indonesia. Batam : Karisma Publishing Group

http://www.pengertianahli.com/2015/01/pen gertian-identifikasi.htm

Chien, lie. 2011. Ketel uap http://liechienlichin.blogspot.co.id/?m=1 (di unduh pada tanggal 14-04-2016 13.35)

Dinata, Sukma. 2006. Metode Penelitian Kualitatif. Bandung : ALFABETA

Gunawan, imam 2013," metode penelitian kualitatif",'malang, PT bumi aksara

Hanavie, Fauzi. 2012. Ketel uap. http://ziehan96.blogpot.co.id/2012/06 (di unduh pada tanggal 12-04-2016 10.36).

Instruction Manual Book. 1998. Approval Manual for Boiler Plant. Eropa, yugoslavia, Japan.

J. Moleong, Lexy. 2001. Metode Penelitian Kualitatif dan Kuantitatif. Jakarta

Sugiono. 2010. Metode Penelitian Kualitatif. Bandung : ALFABETA

Tambunan. 1984. Ketel Uap. Jakarta : Karya Agung

Van der veen. T. 1977. Tehnik Ketel Uap. Uitgevers Europese Educatieve Groepm, Vleuten. 